\title{
PERBANDINGAN PENURUNAN TEKANAN DARAH PASIEN BEDAH FRAKTUR DENGAN PREMEDIKASI ANESTESI PETIDIN DAN FENTANIL DI RSUD KOTA BOGOR
}

\author{
Siti Mariam*, Kiki Fitriana Dewi, Halimatussa'diyah \\ Program Studi S1 Farmasi, Sekolah Tinggi Teknologi Industri dan Farmasi, Bogor \\ *Korespondensi: sitimariam210467@gmail.com
}

\begin{abstract}
ABSTRAK
Premedikasi anestesi intravena menggunakan obat petidin dan fentanyl menimbulkan efek samping hipoventilasi atau penurunan volume tidal serta hipotensi. Penelitian ini bertujuan untuk mengetahui penurunan tekanan darah pada pasien bedah fraktur di RSUD Kota Bogor. Penelitian ini dilakukan pada 100 pasien rawat inap pada periode Januari-Desember 2018 yang diberi premedikasi obat petidin dan fentanil. Jenis penelitian non eksperimental dengan pengambilan data secara Retrospektif, data hasil penelitian dianalisis menggunakan uji Kolmogorov-Sminorv test dan uji Mann Whitney test. Data yang diambil meliputi: Nomor rekam medis, umur, jenis kelamin, durasi operasi dan tekanan darah 5 menit sebelum premedikasi dilakukan sampai 1 jam operasi berlangsung. Hasil penelitian ditemukan pasien bedah fraktur lebih bayak terjadi pada laki-laki (63\%) dengan rentang usia 40-50 tahun (29\%). Durasi yang paling banyak operasi selama 1 jam (62\%). Terapi premedikasi yang paling banyak digunakan sebagai obat analgetik narkotik adalah fentanil (70\%). Penurunan tekanan darah yang paling banyak terjadi adalah petidin $(13,93 \mathrm{mmHg})$ dibanding dengan fentanil $(8,34 \mathrm{~mm} / \mathrm{Hg})$. Berdasarkan hasil statistika menggunakan uji Kolmograv-Smirnov test dan uji Mann-Whitey test nilai p (asymp sig.(2-tailed) menunjukkan hasil $p$-value $0,05(0,000)$ yang artinya adanya perbedaan bermakna penurunan tekanan darah antara pemberian petidin dan fentanil.
\end{abstract}

Kata kunci: Fentanil, Petidin, Penurunan Tekanan Darah, Premedikasi

\begin{abstract}
Premedication of intravenous anesthesia using the drugs petidine and fentanyl causes side effects of hypoventilation or decreased tidal volume and hypotension. This study aims to determine the decrease in blood pressure in fracture surgery patients at RSUD Kota Bogor. This study was conducted on 100 inpatients in the January-December 2018 period who were given the drugs petidine and fentanyl premedication. This type of non-experimental research with the retrospective data collection, research data were analyzed using the Kolmogorov-Sminorv test and the Mann Whitney test. Data taken included: Medical record number, age, sex, duration of surgery and blood pressure 5 minutes before premedication to 1 hour of surgery. The results found more surgical fracture patients occur in men (63\%) with an age range of 40-50 years (29\%). The duration of the most operations was 1 hour $(62 \%)$. The most widely used premedication therapy as a narcotic analgesic drug is fentanyl (70\%). The most common decrease in blood pressure is petidine (13.93 $\mathrm{mmHg}$ ) compared to fentanyl $(8.34 \mathrm{~mm} / \mathrm{Hg})$. Based on statistical results using the KolmogravSmirnov test and the Mann-Whitey test p-value (asymp sig. (2-tailed) showed a p-value of 0.05 $(0,000)$ which means that there is a difference in blood pressure reduction between petidine and fentanyl.
\end{abstract}

Keywords: Anesthesia, Fentanyl, Phetidine, Decrease in Blood Pressure 


\section{PENDAHULUAN}

Pembedahan atau operasi merupakan tindakan invasif dengan membuka bagian tubuh untuk perbaikan (Sjamsuhidajat \& Jong, 2010). Hampir semua tindakan pembedahan dilakukan di bawah pengaruh anestesi, dan diantaranya dilakukan dengan anestesi umum. Anestesi umum adalah suatu keadaan reversible yang mengubah status fisiologis tubuh, yang ditandai dengan hilangnya kesadaran (sedasi), hilangnya persepsi nyeri (analgesi), hilangnya memori (amnesi) dan relaksasi (Holder, 2012).

Selama prosedur anestesi berlangsung akan terjadi perubahan kardiovaskuler dan hormon pemicu stress, sehingga perlu dilakukan monitoring suhu tubuh, fungsi kardiovaskuler, pernafasan, dan kesadaran pasien (Maliowska, 1989; Wiroatmodjo, 2000). Anestesi umum sering memiliki efek yang tidak diinginkan sebagai tambahan dari efek yang diharapkan pada sistem saraf pusat (SSP). Semua obat anestesi intravena dan inhalasi menyebabkan depresi sistem kardiovaskular dan sistem respirasi (Gwinnutt, 2011).

Sebagian pasien mengalami pemulihan dari anestesi dengan lancar secara bertahap dan tanpa keluhan, namun kenyataannya akibat stress pasca bedah dan anestesi sering dijumpai hal-hal yang tidak menyenangkan (Latief, Suryadi \& Dachlan, 2007). Pasien yang mengalami komplikasi pasca operasi dengan general anesthesia yang tidak segera ditangani akan berdampak kematian bagi pasien. Komplikasi yang sering terjadi meliputi komplikasi respirasi (bronkospasme, hipoventilasi, obstruksi jalan nafas, hiperventilasi), komplikasi kardiovaskuler (hipertensi, distritmia jantung, trombosis vena, embolisme paru) hipotermia, hipertermia dan gelisah pasca operasi (Boulton, 1994). Oleh karena itu untuk menggurangi terjadinya efek yang tidak diinginkan dari pemberian anestesi, maka dilakukan tindakan premedikasi dan post medikasi.

Premedikasi merupakan suatu rangkaian anestesi umum berupa pemberian obat satu sampai dua jam yang biasanya diberikan beberapa saat sebelum tindakan induksi anestesi dengan tujuan meredakan kecemasan dan ketakutan, memperlancar induksi anestesi, mengurangi sekresi kelenjar ludah dan bronkus, mengurangi isi cairan lambung, megurangi refleks yang membahayakan.

Petidin dan Fentanil digunakan sebagai obat premedikasi karena mempunyai batas keamanan yang lebih besar dan dapat mencapai efek opioid yang diinginkan. Sedangkan kerugian obat premedikasi petidin dan fentanil, yaitu terjadi hipoventilasi atau penurunan volume tidal serta hipotensi. Efek hipoventilasi dan hipotensi dari fentanil lebih rendah dibanding petidin, serta efek analgesiknya lebih kuat dibandingkan petidin. Oleh karena itu perlu dilakukan penelitian bagaimana pengaruh pemberian petidin dan fentanil terhadap tekanan darah pasien sebelum dan selama tindakan operasi bedah fraktur.

Penelitian ini akan dilakukan di RSUD Kota Bogor, karena berdasarkan hasil Sistem Pelaporan Narkotik dan Psikotropik (SIPNAP) hasil penggunaan obat narkotik khususnya fentanil dan petidin merupakan obat narkotik yang sering digunakan pada saat proses operasi sedang berlangsung. Obat golongan narkotik ini memiliki efek analgesik yang cukup kuat untuk meredakan rasa sakit.

\section{METODE PENELITIAN}

Desain penelitian Cross- Sectional dengan pengambilan data secara Retrospektif dengan penyajian data secara deskriptif. Data dianalisis untuk membandingkan efek penurunan tekanan darah dari pasien bedah fraktur yang diberi obat premedikasi petidin dan fentanil pada periode bulan Januari 2018- Desember 2018 di RSUD Kota Bogor. Kriteria inklusi pada penelitian ini adalah pasien usia 15 - 50 tahun yang diberi premedikasi petidin atau fentanil dan tidak menggunakan obat penurun darah. Kriteria eksklusi yaitu pasien yang menggunakan premedikasi kombinasi petidin dan fentanil dan data rekam medis yang tidak terbaca.

\section{HASIL DAN PEMBAHASAN}

Hasil penelitian diperoleh sebanyak 100 pasien bedah fraktur pada periode Januari 2018 - Desember 2018 yang telah menjalani operasi di Instalasi bedah RSUD Kota Bogor yang terdiri dari $63 \%$ laki-laki dan $37 \%$ perempuan.

Dalam penelitian ini fraktur lebih banyak disebabkan karena kecelakaan lalu lintas, pasien laki-laki yang mengalami fraktur lebih banyak dibandingkan perempuan karena aktivitas laki-laki lebih banyak di luar rumah yang berhubungan dengan pekerjaan yang lebih berat dari pada perempuan.

Berdasarkan usia hasil penelitian menunjukkan persebaran yang seimbang, persentasi pasien berdasarkan usia pada gambar di bawah: 


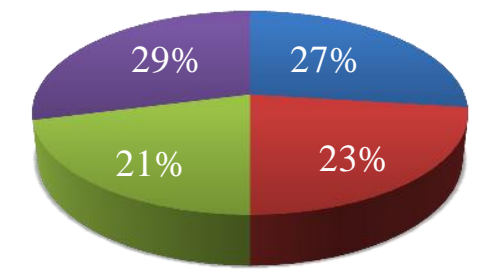

चsia 15-20 चsia > 20-30

च Usia > 30-40 घ Usia > 40-50

\section{Gambar 1. Usia Pasien Bedah Fraktur}

Pasien bedah fraktur paling banyak usia 40-50 tahun $(29 \%)$ karena pada usia tersebut kekuatan tulang pasien mulai berkurang dan mengalami pengeroposan tulang atau osteoporosis (Gibney, 2009). Usia 15-20 tahun (27\%) merupakan usia remaja dimana fraktur terjadi disebabkan oleh kecelakaan lau lintas.

\section{Durasi Anestesi Bedah Fraktur}

Berdasarkan Mansjoer (2000), secara garis besar pembedahan dibedakan menjadi dua, yaitu pembedahan mayor dan pembedahan minor Istilah bedah minor (operasi kecil) dipakai untuk tindakan operasi ringan yang biasanya dikerjakan dengan anestesi lokal, seperti mengangkat tumor jinak, kista pada kulit, sirkumsisi, ekstraksi kuku, penanganan luka. Sedangkan bedah mayor adalah tindakan bedah besar yang menggunakan anestesi umum/ general anestesi, yang merupakan salah satu bentuk dari pembedahan yang sering dilakukan (Sjamsuhidajat dan Jong, 2005). Anestesi umum merupakan teknik anestesi yang paling sering digunakan dibandingkan dengan teknik anestesi lain. 70-80 persen kasus pembedahan memerlukan tindakan anestesi umum (Absalom, 2010). Waktu yang dibutuhkan

\section{Gambaran Penurunan Tekanan Darah Pasien Bedah Fraktur}

Hasil pengukuran tekanan darah pasien yang diberikan premedikasi petidin atau fentanil yang dilakukan 5 menit sebelum anestesi dan pengukuran 1 jam saat operasi berlangsung di bawah pengaruh anestesi menunjukkan adanya penurunan tekanan darah. Penurunan tekanan darah dapat dilihat pada gambar di bawah. pasien untuk pulih sadar setelah diberikan anestesi berbeda-beda bergantung pada teknik anestesi, lama operasi, lama anestesi, dan jenis obat yang digunakan (Arvianto, 2017). Durasi operasi berdasarkan hasil penelitian ditunjukkan pada gambar di bawah.

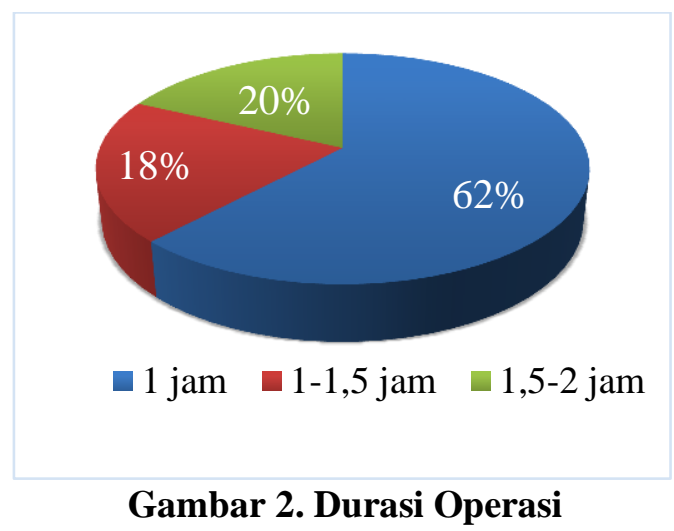

Hasil penelitian menunjukkan durasi operasi terbanyak selama 1 jam (62\%). Bedah fraktur termasuk bedah mayor, dengan durasi atau lamanya pengaruh anestesi selama operasi membutuhkan waktu 1-2 jam.

\section{Penggunaan Obat Premedikasi}

Berdasarkan hasil penelitian diperoleh data penggunaan obat analgeik narkotik fentanil (70\%) lebih banyak dibanding dengan petidin (30\%). Hal ini disebabkan karena efek analgetik fentanil lebih kuat dari petidin. Potensi analgetik fentanil 75-125 kali lebih kuat dari pada petidin. Efek kerja petidin lebih cepat, durasi kerjanya lebih singkat sedangkan fentanil memiliki waktu paruh eliminasi 3-4 jam sehingga bekerja lebih lama (Dinas Kesehatan, 2010).

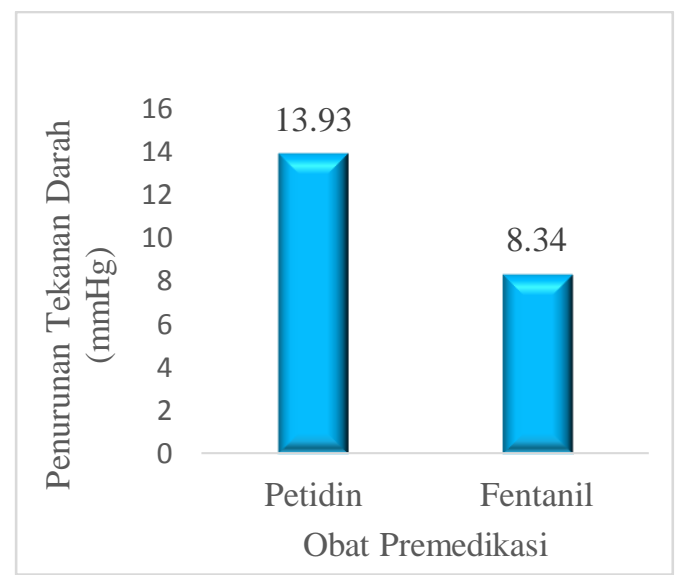

Dari gambar di atas terlihat penurunan tekanan darah dari pasien yang diberikan premedikasi petidin lebih tinggi dibanding 
pemberian premedikasi fentanil. Selisih penurunan tekanan darah antara petidin dan fentanil sebesar 5,59 mm Hg. Petidin mampu menggantikan histamin dari ikatannya di sel mast dan histamin dilepaskan ke dalam sirkulasi yang akan menyebabkan vasodilatasi perifer dan hipotensi. Jumlah dari pelepasan histamin dan derajat hipotensi mungkin dihubungkan oleh dosis, khususnya saat disuntikkan secara intravena. Hipotensi yang dihasilkan dari pelepasan histamin pada induksi opioid dapat dihambat dengan kombinasi H1$\mathrm{H} 2$-antihistamin. Berbeda dengan dengan petidin, fentanil menghasilkan efek anestesi yang maksimum dengan pengeluaran histamin yang lebih sedikit, depresi kardiak secara langsung, serta serangan atau kejang pada grand mal (Nunn, Utting, Brown, 1989).

Hasil ini sejalan dengan hasil penelitian Susiyadi (2016) di RSUD Prof. Dr. Margono Soekarjo yang menyatakan bahwa anestesi intravena fentanil mempunyai efek hipotensi lebih sedikit dibanding dengan petidin, dan terdapat perbedaan yang bermakna antara pemberian petidin dan fentanil pada tekanan darah sistol, tekanan darah diastolik, tekanan darah Mean Arterial Pressure (MAP) sebagai anestesi intravena pada menit 0 hingga 5 menit ke 3. Penelitian Annisa (2010) di Rumah Sakit Slamet Riyadi Surakarta menunjukkan bahwa anestesi intravena dengan menggunakan fentanil mempunyai efek hipotensi lebih sedikit dibanding dengan menggunakan petidin.

Berdasarkan hasil statistika menggunakan uji Kolmograv-Smirnov test dan uji MannWhitey test nilai $\mathrm{p}$ (asymp sig. (2-tailed) menunjukkan hasil nilai $\mathrm{P}$ value $<0,05$ $(\mathrm{p}=0,000)$ yang artinya ada perbedaan antara pemberian petidin dan fentanil.

\section{SIMPULAN}

Dari hasil penelitian dapat disimpulkan bahwa dari 100 pasien yang telah menjalani operasi bedah fraktur di instalasi Bedah RSUD Kota Bogor Periode Januari-Desember 2018 yang mendapat premedikasi petidin dan fentanil lebih banyak laki-laki (63\%), rentang usia paling banyak usia 40-50 tahun (29\%) dan durasi operasi terbanyak selama 1 jam (62\%). Obat premedikasi yang paling banyak digunakan adalah fentanil (70\%), efek penurunan tekanan darah dari premedikasi obat petidin sebesar $13,93 \mathrm{mmHg}$ dan fentanil sebesar $8,34 \mathrm{mmHg}$ dengan selisih penurunan tekanan darah $5,59 \mathrm{mmHg}$. Uji statistik menggunakan uji Kolmograv-Smirnov test dan uji Mann-Whitey test nila $\mathrm{p}$ value $<0,05$
$(\mathrm{P}=0,000)$ menunjukan adanya perbedaan yang nyata terhadap penurunan tekanan darah.

\section{DAFTAR PUSTAKA}

[1] Absalom, A.R., Struys, M. Overview of Target Controlled Infusions and Total Intravenous Anaesthesia. Edisi ke 2. 2007. English: Academia Press. 2. Absalom, A. R., Sutcliffe N., Kenny.

[2] Annisa, Fadhlina (2010), Perbandingan Perubahan Tekanan Darah Dan Laju Nadi Antara Pemberian Petidin dan Fentanil Sebagai Premedikasi Anestesi (Skripsi) Universitas Sebeles Maret Surakarta.

[3] Arvianto dkk, 2017, Perbandingan antara Sevofluran dan Propofol Menggunakan Total Intravenous Anesthesia Target Controlled Infusion terhadap Waktu Pulih Sadar dan Pemulangan Pasien pada Ekstirpasi Fibroadenoma Payudara, Jurnal Anestesi Perioperatif [JAP. 2017;5(1): Departemen Anestesiologi dan Terapi Intensif Fakultas Kedokteran Universitas Padjadjaran/Rumah Sakit Dr. Hasan Sadikin Bandung.

[4] Boulton T., Blogg C., 1994. Komplikasi dan Bahaya Anestesi: Anestesiologi. EGC. Jakarta: 229-231.

[5] Dinas Kesehatan, 2010. Pethidin. http://www.diskes.jabarprov.go.id.

[6] Dinas Kesehatan, 2010. Phentanyl. http://www.diskes.jabarprov.go.id.

[7] Gwinutt C., 1997. Drugs Asociated with Anaesthesia. Measurement andMonitorng : Clinical Anaesthesia. University of Manchester. Oxford. Hlm: 53-54; 79-84.

[8] Holder A. Sedation. Diunduh dari: http:// emedicine.medscape.com/ article/ 809993-overview\#showall Diakses : Agustus 2012 [3]Malinowska M., et al., 1998. Influence of propofol and Ketamin in TIVA Laparoscopic Surgery on some Haemodynamic and Biochemical Stress Reaction Parameters.Med Sci Monit: 661-664 
22 Siti Mariam et al., (Perbandingan Penurunan Tekanan Darah Pasien Bedah...)

[9) Masjoer A, Suprahaita, Wahyu IW, Wiwik S, 2000. Kapita Selekta Kedokteran. Edisi 3. Jilid 2. Media Aesculapius. Jakarta: 24-27.

[10] Nunn J.F., Utting J.E., Brown Jr Burnel R., 1989. General anaesthesia. 5th edition.

[11] Susiyadi, Refni Riyanto (2016) Pengaruh Pemberian Petidin Dan Fentanyl Sebagai Premedikasi Anestesi Terhadap Perubahan Tekanan Darah Di RSUD Prof.DR.Margono Sokarjo, Jurnal SAINTEKS Volume XIII No 2, Oktober 2016: 49-55.

[12] Wirjoatmojo K, 2000. Anestesiologi dan Reanimasi Modul Dasar untuk Pendidikan S1 Kedokteran. Direktorat Jendral Pendidikan Tinggi Departemen Pendidikan Nasional. Jakarta: 150-158. 